\title{
DETECTION OF RESTORATION WORK BY APPLYING THE RANSAC ALGORITHM TO THE POINT CLOUD DATA FROM LASER SCANNING: CASE STUDY AT OSTIA
}

\author{
Y. B. $\operatorname{Lim}^{1}$, T. Ogawa ${ }^{2}$, Y. Hori ${ }^{3}$ \\ ${ }^{1}$ Faculty of Human-Environment Studies, Kyushu University, 744, Motoka, Fukuoka- lim.yong.292@s.kyushu-u.ac.jp \\ ${ }^{2}$ Faculty of Human-Environment Studies, Kyushu University, 744, Motoka, Fukuoka- ogawa.takuro.326@m.kyushu-u.ac.jp \\ ${ }^{3}$ Faculty of Human-Environment Studies, Kyushu University, 744, Motoka, Fukuoka - hori@ arch.kyushu-u.ac.jp
}

Commission II

KEY WORDS: Laser scanning, RANSAC algorithm, Restoration, Roman building, Ostia

\begin{abstract}
:
In Ostia, the huge range of excavation carried out by Guido Calza under Mussolini (1938-1942), the zone of contiguous city blocks unearthed in those massive campaigns. From 2012, new survey by a Japanese team of standing remains using laser scanners formed the basis for an analysis of building history, and for a reconstruction of the original building. There is a considerable amo unt of undocumented reconstruction work in the upper part of the structure which has been identified from analysis of the surface of the walls. The seam and the absence of coursing between the original walls and the later restored works sometimes including in the Roman phase, and sometimes modern using original part of the walls, make difficult to identify which part of walls were or iginal and which were restorations or re-use 80 years later from the excavation. In this paper, the case that the seams are invisible, but its existence is known from the photographic record of the progress of the excavations. The detection by applying the RANSAC algorithm to the point cloud data from laser scanning relies on several cases of invisible seams running on the surfaces. Additionally, this method allows us without any special knowledge and experience to find detailed characteristics on the surface of the walls, such as slight unevenness or weathering parts, to extrapolate the building history.
\end{abstract}

\section{INTRODUCTION}

The recording of position, dimensions and shape is a necessary and inevitable process of almost every project related to the conservation of historical buildings, forming an important element of the documentation and analysis of building history. For example, we have to know the size and shape of a building in an ancient Roman city can, which can help archaeologists identify its significance, to know how cross vaults were constructed helps a conservator to determine the appropriate action for its protection and preservation, while simply having access to an accurate record of a building façade helps a manager or a director to schedule the work for its restoration. It is common to present such measurements as plans, sections and profiles plotted on hardcopy for direct use on archaeological site but, with the laser scanners providing three-dimensional measurement, it is possible to generate three-dimensional survey information.

This paper shows the case studies of available technology applying RANSAC algorithm to know detailed feature of the surface of the ancient walls. In architectural planning based on BIM 3D modelling, RANSAC algorithm is applied to generate geometric shapes from the measured point clouds. Laser scanning technology is taking the lead in this aspect. On the other hand, photogrammetry is more common than laser scanning at archaeological sites because it is inexpensive and easy to use. However, archaeologists could not radically acquire computer and laser scanning literacies. In addition, engineers also could lack both knowledge and experience at archaeological sites. It is accepted that photogrammetry enables us to have models with high-resolution vividly textures without carrying a heavy and expensive scanner. Now, what is the advantage of laser scanning over photogrammetry in measurement survey at archaeological sites? This paper indicates that the point cloud data measured by laser scanning is valuable for both long range conservation and research of Roman architecture.

Recently unearthed ruins, included Roman buildings, has been restored for various reasons; weathering, damaged, collapsed, and so on. For example, the ruin, Ostia in Italy, was unearthed in the end of the nineteen centuries at the first times in the scientific excavation. Some old photographs, which show that the modern restorations had been carried out, are preserved in the archive of the archaeological park of Ostia, and they can be still seen. On the other hand, the large-scale excavation has been carried out during 1938 to 1942 , two third area of the whole of ruins were unearthed during these five years. This caused a lot of restorations could not be recorded. Then about eighty years have passed, so few people know every restoration in the ruins. In addition to that, these buildings damage from weathering and salt, consequently continuous restorations are required to guarantee the study of Roman buildings in the present and the next generation. In those reasons, the easy method to trace restoration from unearthed ancient buildings, which anyone can carry out even without archaeologists. Kyushu University has

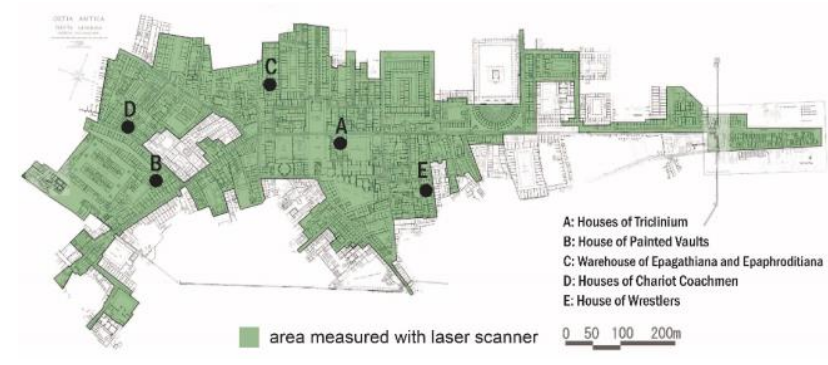

Figure 1. Area measured by laser scanner in Ostia. (Edited by author, and cited from G. Calza, G. Becatti, I. Gismondi,G. de Angelis D'Ossat, H. Bloch, Scavi di Ostia, Vol. 1, Topografia generale. Rome: Libreria dello Stato,1953, appendix.) 


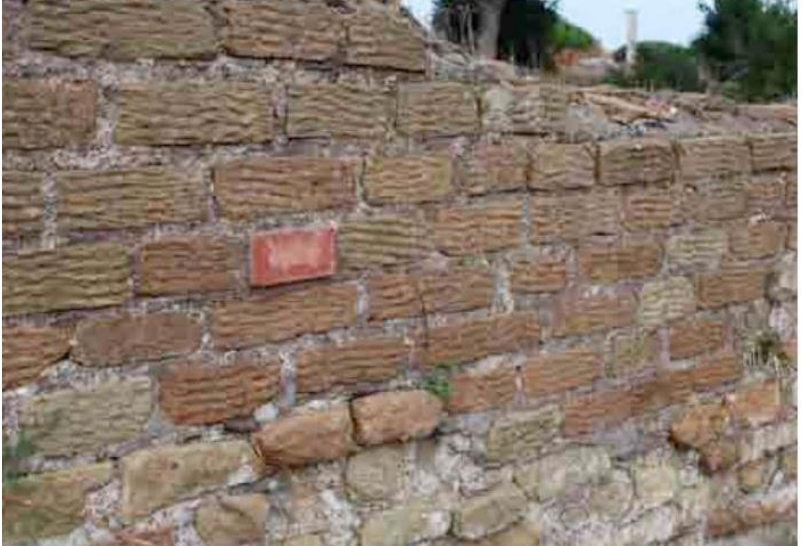

Figure 2. Restoration in Guild Temple with a small plaque with restoration year and scratched bricks [Rinaldi, 2012]

carried out exhaustive laser scanning survey in Ostia since 2012 About eighty percent of the whole has been recorded as point clouds. (Figure 1) Such three-dimensional data is valuable not only for research but also for the conservation of archaeological sites.

This case study is creative in the possibility that archaeologists and engineers can collaborate without having any specific knowledge of each other in the early stage of archaeological analysis or restoration work. Nowadays, RANSAC has become more common and commercial software is equipped with this algorism so anyone can generate geometrical models which are aligned optimally with a point cloud. The authors have experienced the challenges to collaborate archaeologists with engineers through about ten years field survey. This case study is expected to allow both archaeologists and engineers to easily collaborate and interact for development of the sustainable archaeological sites and the study of Roman architecture.

\section{TRACING RESTORATION}

The systematic archaeological excavation at Ostia began in 1907 under the direction of Dante Vaglieri. From 1912, the excavation was led by Guido Calza. As an architect, Italo Gismondi was involved from the beginning of the excavation. About two-thirds of the Ostia site that can be seen today was unearthed between 1938 and 1942. Mussolini suggested this large-scale excavation. Almost all buildings excavated during these five years were restored to introduce Ostia at EUR (Esposizione Universale di Roma) which would be held in Rome in 1942. The details of excavation, information about the places of restoration and reconstruction are scarcely documented. Only a limited number of old photographs captured the scene of excavation.

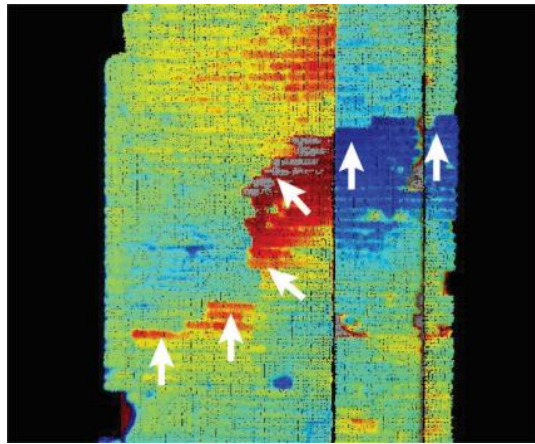

Figure 4. Joint visible in the colour gradation
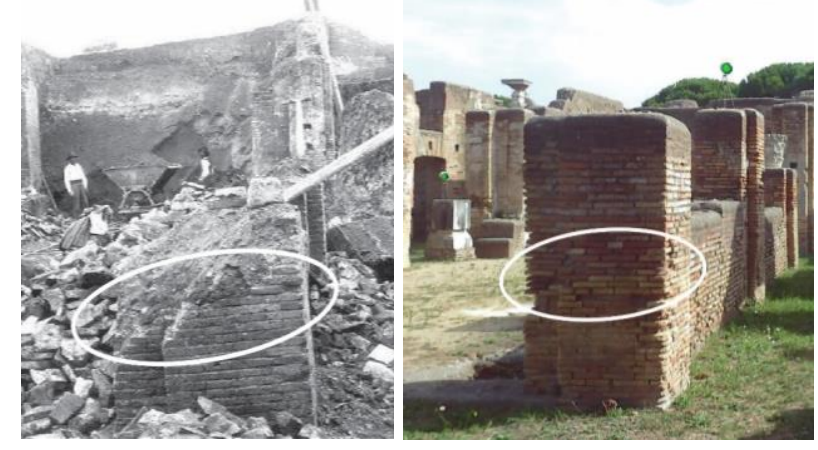

Figure 3. Restoration in Houses of Triclinium [left: old photograph of Parco Archeaologico di Ostia Antica A 2474, right: photograph taken in 2015]

There are two major problems with this large-scale excavation during 1938-42 for research. Firstly, there are few records of the excavation details, and secondly, the large-scale restoration and reconstruction have been carried out without detailed record. Regarding the second problem, it is only possible to confirm the restoration with photos of the excavation site mentioned above (fig. 7, 11, 14, 16) However, except for a few noticeable buildings, the information about restoration and reconstruction of most of the excavated buildings is unknown.

In Ostia site, we still could find some restoration parts which are easy to be differentiated from the original ancient Roman parts. The traces of restoration and reconstruction work are left purposely. For example, the bricks with the restoration year stamped on them are embedded in the restoration areas, and the bricks in the restoration areas are scratched purposely to make it easier to be identified from the ancient Roman remains. (fig 2) Especially during the large-scale excavations, some remains have not been restored in this manner. Thus, it is difficult for later generations of researchers, craftsmen, and technicians to identify the restoration parts without the help of restoration traces. (fig. 3 )

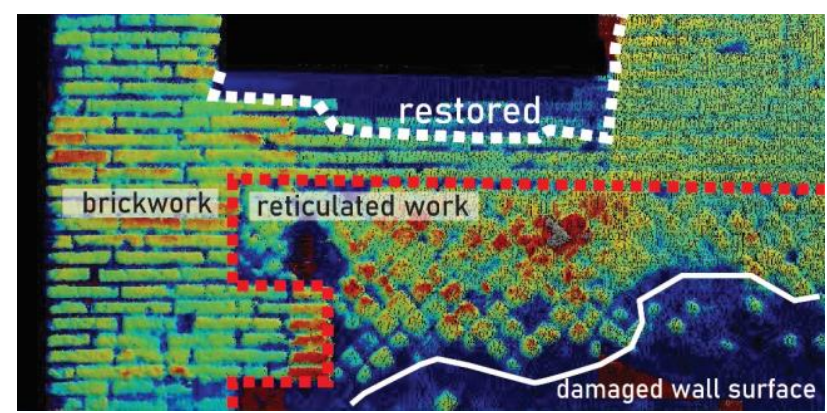

Figure 5. Traces visible in the colour gradation

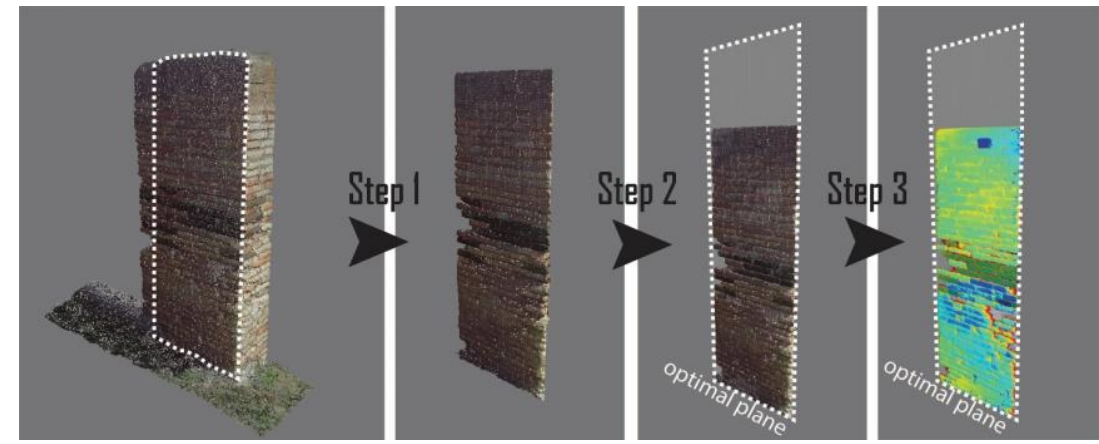

Figure 6. Analysis process 
In this paper, based on the long-term perspective of the problem of restoration and reconstruction of archaeological sites, we propose a method using the RANSAC algorithm that enables researchers who are not familiar with 3D technology and caretakers and technicians who are not familiar with Roman studies to easily identify the restored part. To prove the practicality of the RANSAC algorithm, we focused on the slight change in the boundary between the restoration part and the ancient Roman remains using the point cloud collected via laser scanning since 2012 until the survey was interrupted due to COVID-19.

\subsection{Process}

First, a plane was generated and aligned with a point cloud of a surface within allowed deviation of $1 \mathrm{~mm}$. Second, colour gradation was applied to the point cloud based on the deviation. If the building was restored, joints could be formed because some of the broken parts were patched. Slight differences of surfaces are sometimes showed at the joints, and they are clearly seen in the gradation. (fig. 4)

It is a common way to apply RANSAC algorithm to the least square method to remove gross error while generating a geometrical shape such as a plane which is aligned with the point cloud. The surfaces of the walls or the columns are sometimes irregularly curved due to plasticity of Roman concrete. Such uneven shapes or forms could be the gross error when aligning a plane with the point cloud of a surface of a Roman building.

Step1: Prepare the surface data for analysis

Each surface data of walls or columns should be distinguished and separated.

Step2: Generate optimal planes by RANSAC algorithm

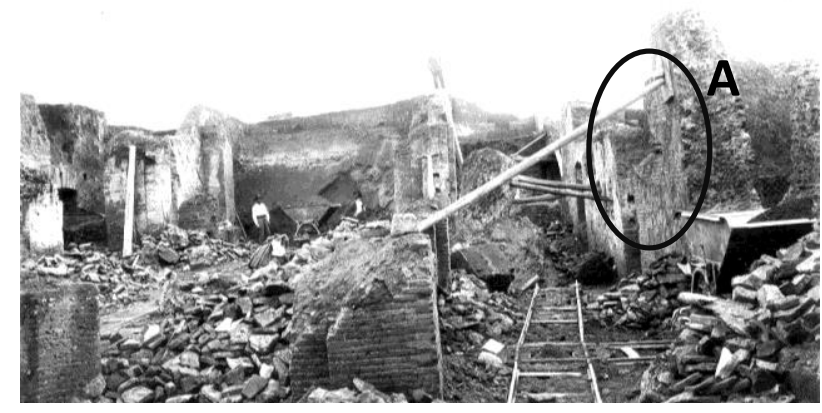

Figure 7. Excavations of the Houses of Triclinium [Old photograph of Parco Archeaologico di Ostia Antica A 2474]
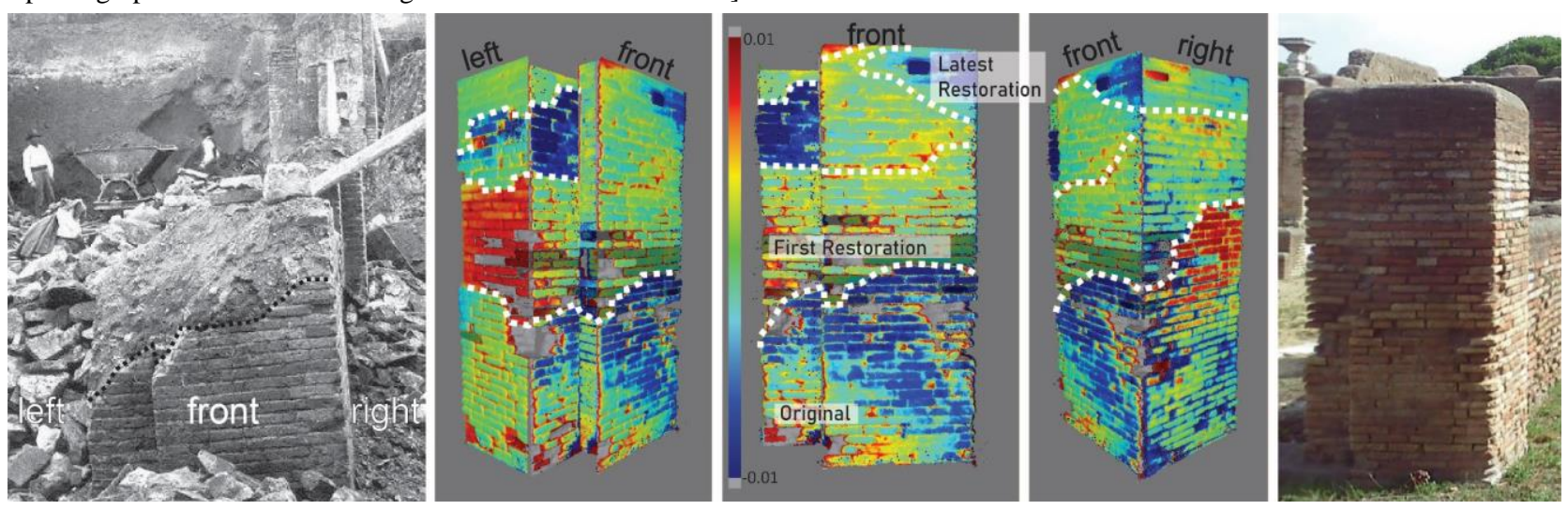

A plane was aligned with each separated point cloud by the least square method applied RANSAC algorithm. An iteration process of RANSAC algorithm is briefly explained below.

1) Select the point cloud. A plane aligns with the point cloud within allowed deviation of $1 \mathrm{~mm}$ by the least square method.

2) Point coordinates in the distance of the plane within $1 \mathrm{~mm}$ are randomly selected with a maximum of 2500 points.

3 ) The plane is aligned again in the same way, then the previous selected points were reset.

4) Iterate operation 2)-3) for 8000 times.

5) The plane which had the highest number of points within the tolerance range, is the most optimal one.

If the most optimal plane covers the whole of the point cloud, move to step 3. Otherwise, the point cloud should be divided into some groups by grid, then retry operation 1 ).

The point cloud was coloured gradations based on the deviation of the surface from the most optimal plane. Points almost on the plane were coloured in green, ones behind the plane are coloured in blue and ones in front are coloured in red. A surface of Roman buildings can be distinguished from a restored surface without archaeological expertise, based on a clear gap in the colour gradations. In this way, some damaged parts were also found out because weathering surfaces of burned bricks or tufa (a kind of limestone) does not perfectly match an optimum plane. Such clearly dividing lines on colour gradations can be regarded as joints between original Roman buildings and restored parts. (fig $4,5)$

We were able to confirm the restored parts from limited old photographs taken during the excavation and restoration. The practicality of these analyses was confirmed by comparing old

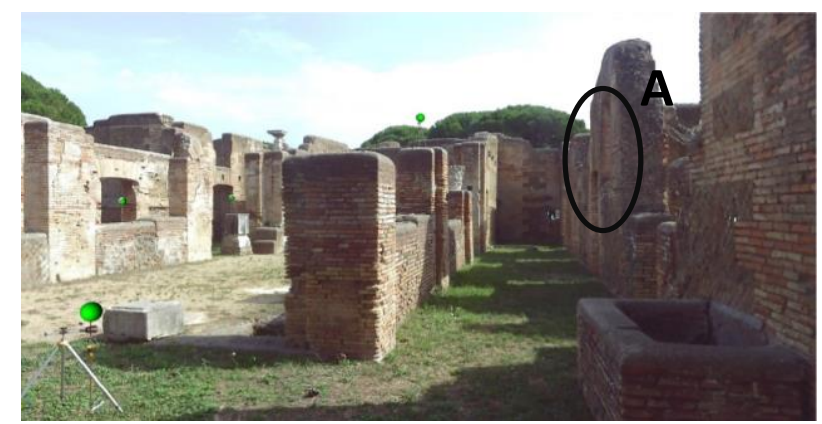

Figure 8. Houses of Triclinium in 2015

Figure 9: Deviations between the plane and the actual surface: the pillar in the courtyard of Houses of Triclinium [first left: old photograph of Parco Archeaologico di Ostia Antica A 2474] 


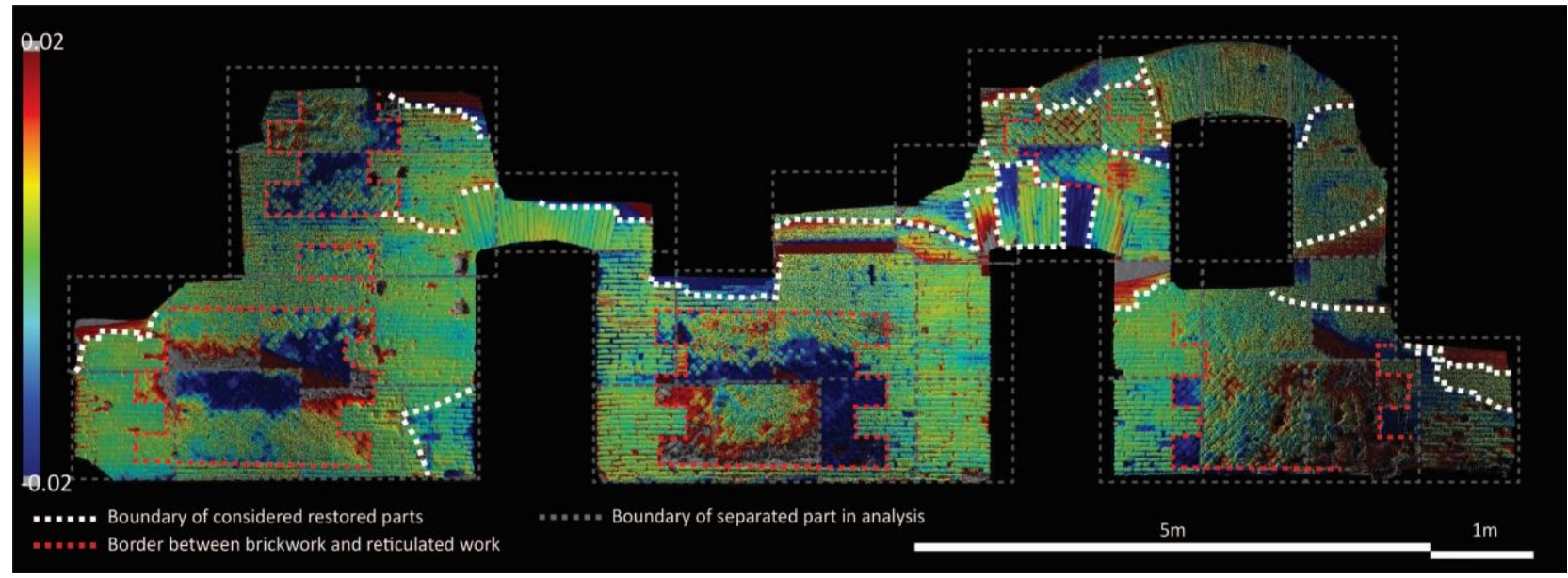

Figure 10: Deviations between the plane and the actual surface: the wall of Houses of Triclinium

photographs with those of the buildings which were taken fortunately during the excavations.

\subsection{Results}

\subsubsection{Houses of Triclinium}

An old photograph depicting the excavation work at Houses of Triclinium is shown in figure 7. Unfinished restoration works can be seen in this figure. In the photograph taken in 2015, the restoration parts could be easily traced comparing with one in the old photograph. (fig. 8) However, it is difficult to distinguish the restored parts from the original Roman building parts without comparing with figure 7 . The edge of the restored part which matches with the edge of the broken column in the old photograph could be seen clearly in figure 9 .This figure suggests that the column may have been restored twice. The first restoration used the same material as the original and left no record of it, while the second restoration is the part that can also be observed by the difference in colour and size of the bricks. The deviation between the plane and the wall on the right side of the excavation photo is shown in figure 10 . The broken section of the higher part of the right wall (circle A in fig.7) can be observed in the photograph of the excavation, however, in the preserved remains it can be observed that the part near the window (circle A in fig.8) was restored. The traces can also be seen in Fig. 10. In addition, the traces of other joints that can be considered as restored parts are also visible.

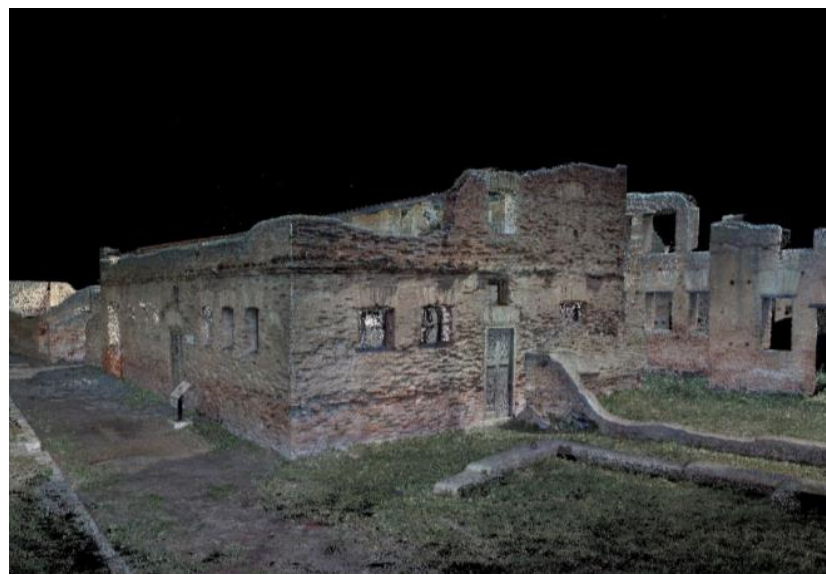

Figure 12. House of Painted Vaults in 2019

Figure 11. Excavation of the House of Painted Vaults in 1939 [Old photograph of Parco Archeaologico di Ostia Antica B 2803]
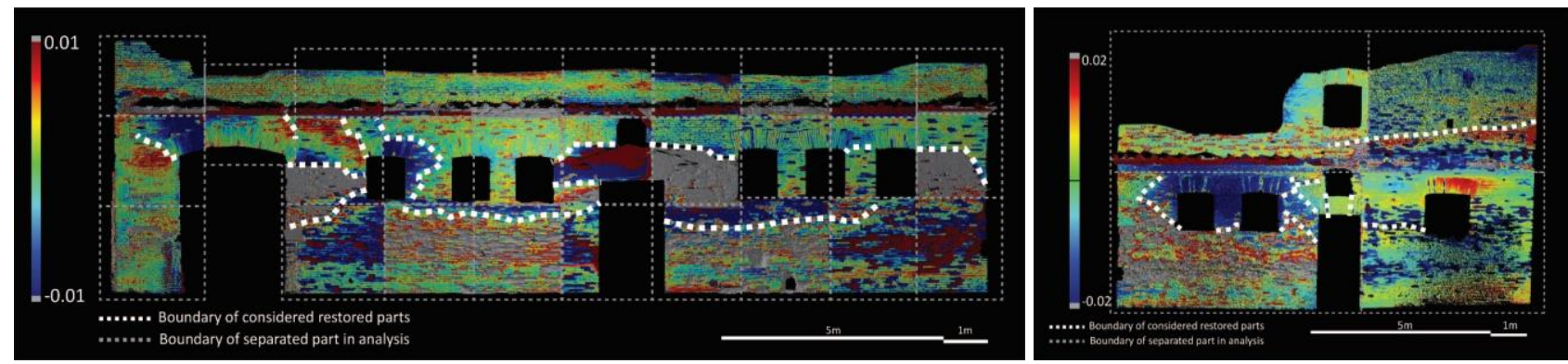

Figure 13. Deviations between the plane and the actual surface: the East (left) and North (right) facade of the House of Painted Vaults 


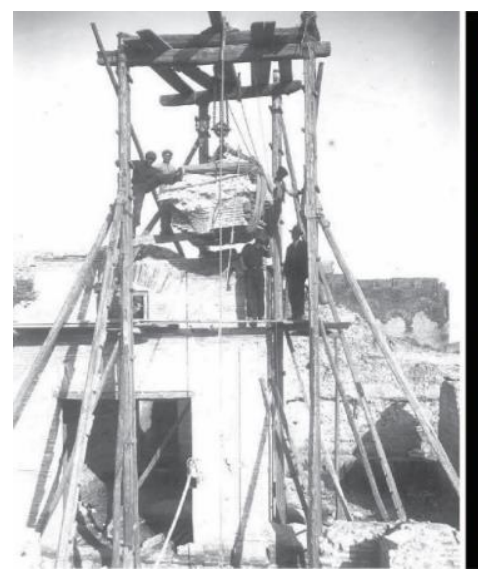

Figure 14. Restoration of the

Warehouse of Epagathiana and

Epaphroditiana. [Old photograph of

Parco Archeaologico di Ostia Antica B2274]

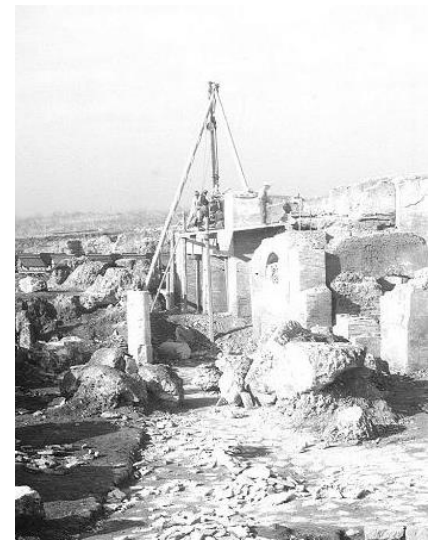

Figure 16. Restoration of the

Houses of Chariot Coachmen (1939). [Old photograph of Parco Archeaologico di Ostia Antica B2765]

\subsubsection{House of Painted Vaults}

By comparing the excavation photo with the remains nowadays, the higher parts in the façade of House of Painted Vaults have been restored. (fig. 11, 12) A few dividing lines are observable without analysis. These dividing lines are probably caused during the restoration. Other than these visible dividing lines, more uneven parts which could be considered as the joint of the restoration were also observed from the parts showing a clear gap in the colour gradation in Figure 13.

\subsubsection{Warehouse of Epagathiana and Epaphroditiana}

Figure 14 was taken during the restoration work at Warehouse of Epagathiana and Epaphroditiana. From the photo, we can see that the upper part of the wall was being restored. However, there is difficult to identify the restoration in the other part of the wall. The analysis result in figure 15 shows that the wall is probably restored. There is a visible part showing a clear gap in the colour gradation on the left and right sides of the entrance at a height of approximately two meters. The colour change in this part shows continuous and obvious. It extends from the inner side of the entrance to the edge of the wall.

\subsubsection{Houses of Chariot Coachmen}

In Houses of Chariot Coachmen, the restoration work was going on when the photo was taken in 1939. (fig. 16) Compared with the coloured point cloud, the exterior wall with the windows was reconstructed. There are several clearly visible and continuous parts showing a clear gap in the colour gradation from one end of the wall to the other. (fig. 17) These could be the joint between the restored section and the original wall.

\subsection{Evaluation of visualising restoration trace}

The optimal planes generated by RANSAC algorithm are aligned with the point cloud. By showing the deviation between the plane and the actual surface in colour gradation, the unevenness of wall surfaces could be observed easily. By comparing the old photographs taken before or during restorations to the coloured point clouds, this analysis method has proved possible to identify the restored part. This method can be applied to other buildings that were restored without detailed record.

\section{DETECTING THE CHANGE OF BUILDINGS}

It is difficult to conserve almost all buildings in Ostia such as roofing over them due to its large scale. Except for wall paintings or mosaics, which would be protected by roofing or glass, most buildings in Ostia are exposed to the weather. Almost a century after the excavation of Ostia, what we saw in buildings just after 

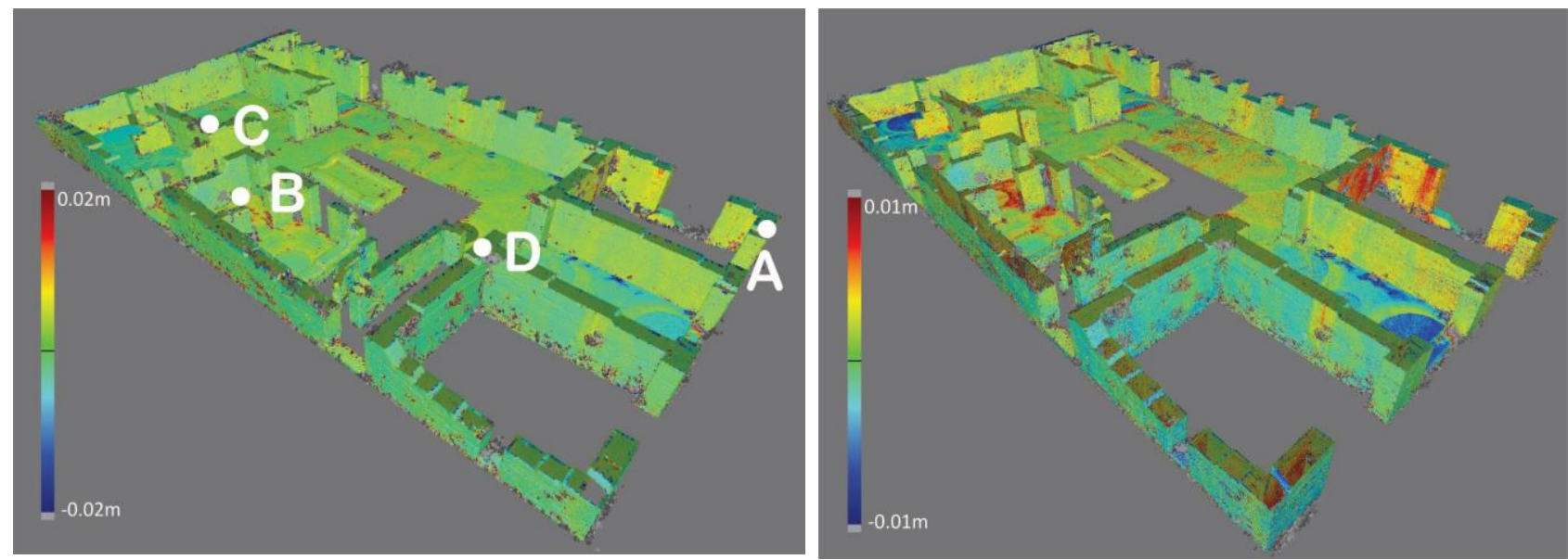

Figure 18. Deviations between the point cloud of 2013 and 2017: the House of Wrestlers

excavations is gradually being lost. Occasionally tracking the changes in the ruins can allow us to find out chipped or weathering parts. However, visual observation or comparison with photographs and drawings can enable us to only find out significant changes such as a collapse. It is difficult to capture slight changes in three-dimension only by comparing photographs. Kyushu University has been conducting comprehensive laser scanning surveys of Ostia since 2012, said above. Some of the buildings have been measured twice or more due to the adaption of new technologies and scanners. In this section, the method to find out changes included slightly chipped or weathering parts through deviation between point cloud, which were measured in different periods, will be demonstrated.

\subsection{Process}

To ensure that the changes in the point clouds measured in year $A$ and year B have not affected each other in alignment and make sure that the changes that exist in the ruins are retained, firstly, the point clouds A and B were registered separately. Then, the point clouds from year $A$ were combined into a single point cloud (point cloud A). The step was repeated in point clouds of year B. Point cloud B was formed. Next, point cloud A and B were compared. Finally, the deviation between point cloud A and B was shown in the colour gradation. In this study, the colour gradation was set to a range of 0.05 to -0.05 . Those outside the display range (greater than 0.05 and less than -0.05) were shown in grey. If there is no change, the point cloud will appear green. The part inclined will show gradient colour.

\subsection{Results}

\subsubsection{House of Wrestlers}

House of Wrestlers was surveyed in 2013 and 2017. The ruins of House of Wrestlers only partly remain in the lower part. Figure 18 shows that the inclination problem did not occur during this five year. Most of the parts are shown in green, which means that the deviation between these two-point clouds is almost 0 . From the comparison result, we found some bricks and stucco (mortar) falling off the wall. (fig. 19) The change in stucco (mortar) falling off is difficult to identify from the figure. In order to make the before and after changes in the mortar easier to identify, we made use of the RANSAC plane analysis explained in the previous chapter. (fig. 20,21)

\subsubsection{Warehouse of Epagathiana and Epaphroditiana}

We carried out surveys in this building, in 2014 and 2017. The wall remaining in Warehouse of Epagathiana and Epaphroditiana
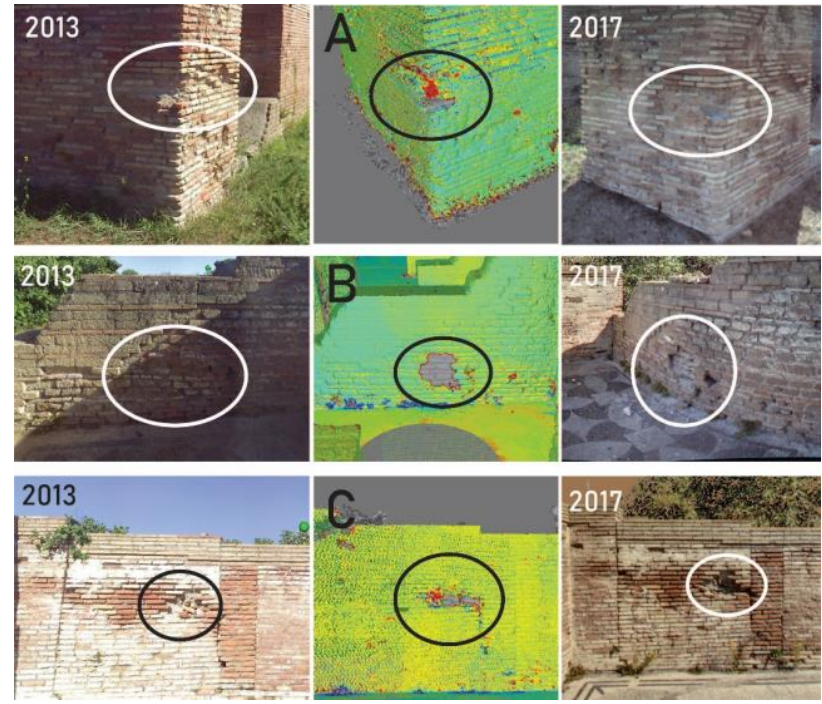

Figure 19. Parts showing changes in the House of Wrestlers

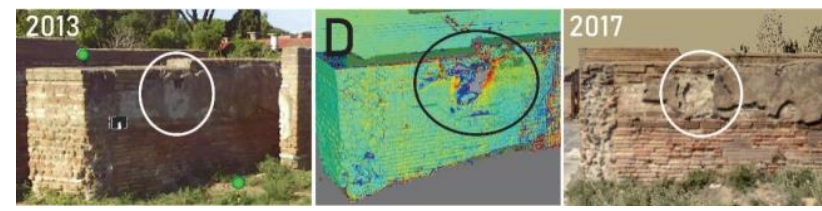

Figure 20. Change in part D of the House of Wrestlers
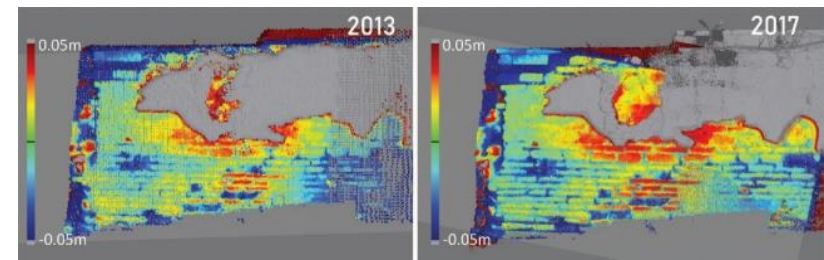

Figure 21. Deviations between the plane and the actual surface: part D of the House of Wrestlers

was higher than in House of Wrestlers, and the risk taken was also higher. However, after comparis on, there are no differences in the point clouds between years either, the whole building showing green. except the part found that the bricks have fallen off the wall (fig.22,23)

From the above two examples we can see that this analysis method allows a quick and clear identification of the change of the remains during the interval of the survey. Although there is 

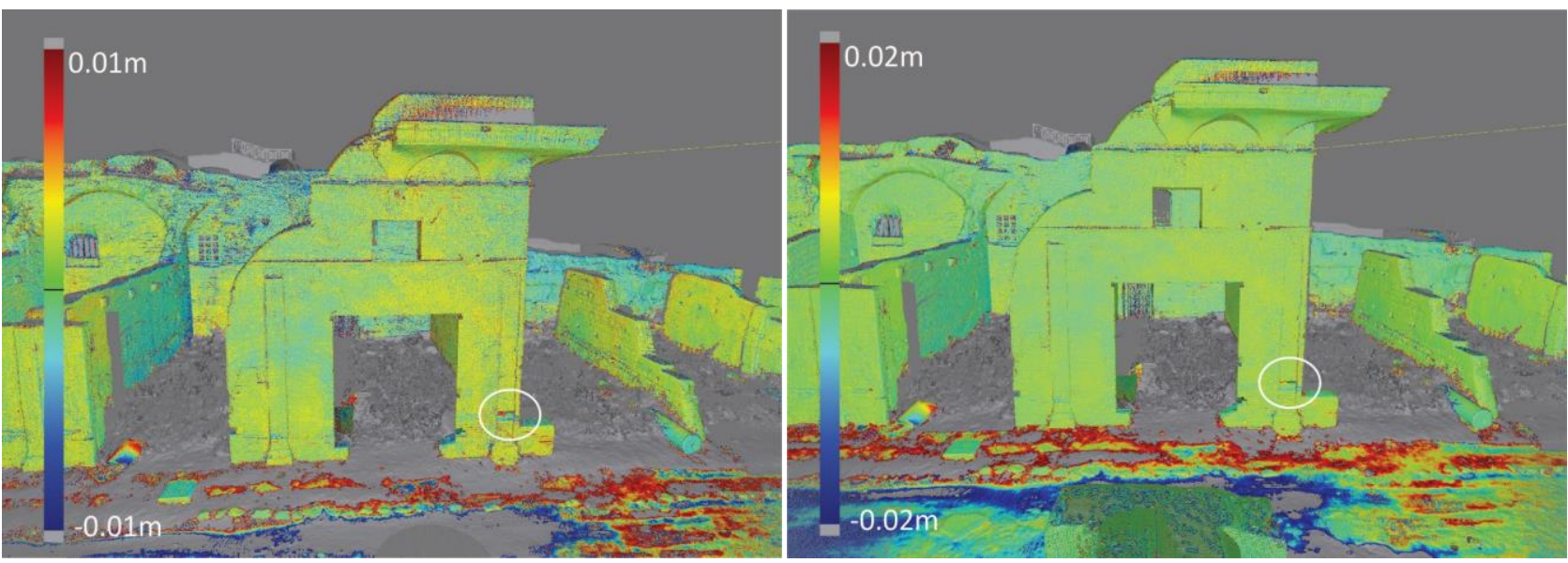

Figure 22. Deviations between the point cloud of 2014 and 2017: the Warehouse of Epagathiana and Epaphroditiana
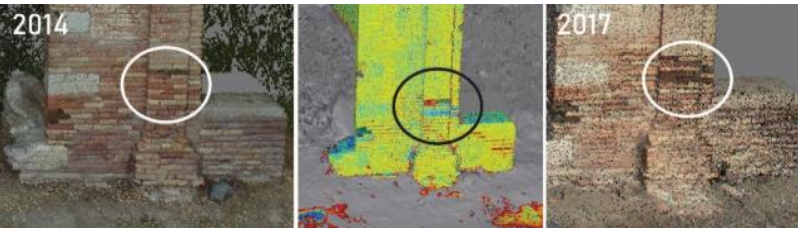

Figure 23. Part showing changes in the Warehouse of Epagathiana and Epaphroditiana

no inclination of structure found in this survey, we need to follow up for a long time to confirm this. The use of point cloud data, which would normally be used only as a record, allows easy detecting the changes in the remains and improves the efficiency of the site management.

\section{CONCLUSIONS}

Two methods of using point clouds to improve efficiency in the management of remains are described above. Firstly, the application of the RANSAC algorithm which can aligned a plane with the point cloud allows the visualisation of the restoration part in the remains. Secondly, the method to find out chipped or weathering parts of Roman buildings through occasionally measured point clouds was demonstrated.

Laser scanning is a more common method to record remains. These methods could be catalysts among engineers and archaeologist to improve managements of remains, also archaeological research.

\section{ACKNOWLEDGEMENTS}

The authors would like to acknowledge Parco Archeologico di Ostia Antica for permission to carry out this work, and support on site at Ostia.

\section{REFERENCES}

Artese, S., Lerma, J. L., Aznar Molla, J., Sánchez, R. M., and Zinno, R., 2019. Integration of surveying techniques to detect the ideal shape of a dome: the case of the Escuelas Pías Church in Valencia. Int. Arch. Photogramm. Remote Sens. Spatial Inf. Sci., XLII-2/W9, 39-43. doi.org/10.5194/isprs-archives-XLII-2-W939-2019.

C. Cappelletti, M. Boniardi, A. Casaroli, C. I. De Gaetani, D. Passoni, and L. Pinto, 2019. Forensic Engineering Surveys with UAV Photogrammetry and Laser Scanning Techniques. Int.
Arch. Photogramm. Remote Sens. Spatial Inf. Sci., XLII-2/W9, 227-234.

D. L. Bool, L. C. Mabaquiao, M. E. Tupas, and J. L. Fabila, 2018. Automated Building Detection Using RANSAC from Classified LiDAR Point Cloud Data. Int. Arch. Photogramm. Remote Sens. Spatial Inf. Sci., XLII-4/W9, 115-121.

Hori, Y. and Ogawa, T., 2017. Visualization of the construction of ancient Roman building in Ostia using point cloud data. Int Arch. Photogramm. Remote Sens. Spatial Inf. Sci., XLII-2/W3, 345-352. doi.org/10.5194/isprs-archives-XLII-2-W3-345-2017.

M. A. Fischler and R. C. Bolles, 1981. Random sample consensus: A paradigm for model fitting with applications to image analysis and automated cartography. Communications of the ACM, vol. 24, no. 6, pp. 381-395.

M. Hossein Pouraghdam, M. Saadatseresht, H. Rastiveis, A. Abzal, and M. Hasanlou, "Building Floor Plan Reconstruction from SLAM-based Point Cloud Using RANSAC Algorithm" Int. Arch. Photogramm. Remote Sens. Spatial Inf. Sci., XLII-4/W18, 483-488,2019.

Ogawa, T. and Hori, Y., 2019. Comparison with accuracy of terrestrial laser scanner by using point cloud aligned with shape matching and best fitting methods, Int. Arch. Photogramm. Remote Sens. Spatial Inf. Sci., XLII-2/W9, 535-541. doi.org/10.5194/isprs-archives-XLII-2-W9-535-2019.

R.Raguram, O.Chum, M.Pollefeys, J.Matas, and J.Frahm, 2013. Usac: A universal framework for random sample consensus. IEEE Transactions on Pattern Analysis and Machine Intelligence (PAMI).

Rinaldi E., 2012. Restauro e conservazione a Ostia nella prima meta del Novecento, Roma.

Rinaldi E., 2015. Conservare e 'rivelare' Ostia: per una rilettura dei restauri della prima meta del Novecento", Restauro Archeologico, pp. 46-67. 